\title{
Nanoscale phenomena during the growth of solid solutions on calcite $\{10 \overline{1} 4\}$ surfaces
}

\author{
J.M. Astilleros ${ }^{\mathrm{a}, *}$, C.M. Pina ${ }^{\mathrm{a}}$, L. Fernández-Díaz $^{\mathrm{a}}$, M. Prieto ${ }^{\mathrm{b}}$, A. Putnis ${ }^{\mathrm{c}}$ \\ ${ }^{a}$ Dpto. Cristalografia y Mineralogia, Universidad Complutense, 28040 Madrid, Spain \\ b Dpto. Geologia, Universidad de Oviedo, 33005 Oviedo, Spain \\ ${ }^{\mathrm{c}}$ Institut für Mineralogie, Universität Münster, Corrensstraße 24, D-48149 Münster; Germany
}

\begin{abstract}
This work deals with the growth behaviour of calcite $\{10 \overline{1} 4\}$ surfaces in contact with multicomponent aqueous solutions containing divalent cations $\left(\mathrm{Ba}^{2+}, \mathrm{Sr}^{2+}, \mathrm{Mn}^{2+}, \mathrm{Cd}^{2+}\right.$, or $\left.\mathrm{Mg}^{2+}\right)$. The result is the formation of solid solutions, with calcite or aragonite as one of the end-members. In situ atomic force microscopy has revealed a wide variety of surface phenomena occurring during the formation of these solid solutions. Among them are: (1) the thickening of growth steps and the subsequent dissolution of surfaces followed by the nucleation of secondary three-dimensional nuclei on calcite surfaces, (2) the transition between growth mechanisms, (3) the formation of an epitaxial layer that armours the substrate from further dissolution and (4) the inhibitory effect of the newly formed surface on the subsequent growth (template effect). The two last phenomena can considerably limit coprecipitation as an effective mechanism for divalent metal uptake. All the phenomena described are a consequence of the interplay between thermodynamics, supersaturation of the aqueous solution with respect to the possible solid solutions and the crystallographic control of the surfaces on the cation incorporation, and indicates that there are many differences between the crystal growth of solid solutions and phases with fixed composition.
\end{abstract}

Keywords: Calcite; Solid solution-aqueous solution; Atomic force microscopy; Crystal growth; Mineral surfaces

\section{Introduction}

The incorporation of dissolved metals into the structure of minerals is an important process that can control their mobility and fate on the Earth's crust. Carbonate minerals, particularly calcite and aragonite, are among the most effective minerals capturing metals in aqueous environments. The so-called sorption processes (which include adsorption, absorption and co-precipitation) affect both the composition of natural waters and modify

\footnotetext{
* Corresponding author. Tel.: +34 913944868; fax: +34 913944872 E-mail address: jmastill@geo.ucm.es (J.M. Astilleros).
}

the surface structure and composition of the host mineral phase (Davis et al., 1987; Zachara et al., 1991; Tesoriero and Pankow, 1996). Many recent experimental works have been devoted to (i) detecting sorption processes by monitoring changes in the solution composition (Prieto et al., 2003; Godelitsas et al., 2003) and (ii) studying the chemical composition and structure of the mineral surface by surface-sensitive techniques (Stipp et al., 1992, 2003; Piriou et al., 1997; Sturchio et al., 1997, 1998; Reeder et al., 1999, 2000; Kelly et al., 2003).

Besides its importance in geochemistry and environmental sciences, the interactions of divalent metals 
with mineral surfaces pose a large number of fundamental questions related to different aspects of mineral crystallization, including the influence of such metals in the formation of polymorphs, their effect as modifiers of the crystal morphølogy and their effectiveness as inhibitors of both nucleation and growth.

Although much effort has been devoted to improve -ur understanding of the thermodynamics and kinetics of solid solution precipitation (Glynn and Reardon, 1990; Priet et al., 1997; Rimstidt et al., 1998; Glynn, 2000), there are many aspects of the process that still remain unknown. The nanoscale mechanisms -f the process are among these aspects. The study of such mølecular scale phenømena is especially relevant to understand the formation of crystals with a range of compositions. Growth and dissølution mechanisms of "pure" minerals have been extensively studied by in situ atomic force microscopy (AFM) (Hillner et al., 1992; Bosbach et al., 1995; Liang et al., 1996; Jordan and Rammensee, 1998; Pina et al., 1998a,b, 2000a; Jordan et al., 2001; Bokem et al., 2002; Shiraki et al., 2000; De Giudici, 2002). Phenomena such as the development of particular grøwth steps and twodimensional nuclei shapes, growth anisotropy, and -ther surface processes $\bullet c c u r r i n g$ in the crystallization -f sølid sølutiøns, can alsø be studied using an AFM. By comparing the characteristics and deviations of the growing surfaces of solid solutions with those corresponding to surfaces of pure substances (endmembers), it is possible to obtain information about the nanometric-scale phenomena which lead to the growth of crystals with compositional variability (Pina et al., 2000b; Astilleres et al., 2000, 2002, 2003a,b).

In this study we describe and review in a common

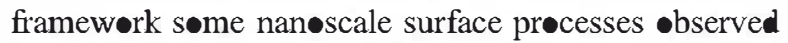
in a number of binary sølid sølution-aque søs søution systems. S॰me of these phenømena exclusively $\bullet c c u r$ when calcite grows from a sølution containing divalent cations larger than $\mathrm{Ca}^{2+}$, while other have only been -bserved when growth $\bullet$ ccurred from a sølution containing cations smaller than $\mathrm{Ca}^{2+}$.

The interaction of sølutions containing cations larger than $\mathrm{Ca}^{2+}\left(\mathrm{Ba}^{2+}\right.$ and $\left.\mathrm{Sr}^{2+}\right)$ with calcite results in twe interrelated effects:

- Thickening of growth steps due to the selective incorporation of such cations in calcite steps containing larger sites and dissolution-recrystallization phenomena after the initial formation of metastable

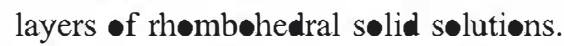

In a different way, when sølutions contain cations smaller than $\mathrm{Ca}^{2+}\left(\mathrm{Mn}^{2+}, \mathrm{Cd}^{2+}\right.$ and $\left.\mathrm{Mg}^{2+}\right)$, the following phenomena has been $\bullet$ bserved:

- Transitions between growth mechanisms. For instance, in the $(\mathrm{Mn}, \mathrm{Ca}) \mathrm{CO}_{3}-\mathrm{H}_{2}$ system, the addition of small amounts of Mn causes the transition from simple step advancement to a two-dimensional nucleation growth mechanism.

- Inhibition of the sorption process due to the formation of a layer which armours the substrate. This effect has been observed during the epitaxial grøwth of $\mathrm{CaCO}_{3}$ on calcite.

Finally, we will devote another section to the template effect, which results from changes in calcite lattice parameters as a consequence of the incorporation of foreign cations. The new substrates inhibit the development of successive layers, leading to the reproduction of the original microtopegraphy.

The understanding of all growth phenomena mentioned above requires a detailed knowledge of thermodynamics of SS-AS systems which is basically determined by the ideality of the sølid solutions, and the difference in the solubility product of the endmembers. Furthermore, since crystal growth takes place at the sølid-aque søs søtion interface, a cœmplete picture of crystal structure, surface nan top graphy and reactivity of the solid phase that acts as a substrate is needed.

\section{Materials and methods}

Nanøscale experiments were carried out using calcite $\{10 \overline{1} 4\}$ surface as substrate. The divalent cations substituting $\mathrm{Ca}^{2+}$ were $\mathrm{Mg}^{2+}, \mathrm{Mn}^{2+}, \mathrm{Cd}^{2+}, \mathrm{Sr}^{2+}$, and $\mathrm{Ba}^{2+}$. All experiments were carrie out at $25^{\circ} \mathrm{C}$ in a fluid cell $\bullet$ a Digital Instruments Multimode Atømic Force Microscope (AFM) working in contact mode. $\mathrm{Ca}^{2+}-\mathrm{M}^{2+}-\mathrm{CO}_{3}^{2-}$ aqueøus sølutions were prepared by mixing $\mathrm{Na}_{2} \mathrm{CO}_{3}, \mathrm{MCl}_{2}$ or $\mathrm{M}\left(\mathrm{NO}_{3}\right)_{2}$ and $\mathrm{CaCl}_{2}$ aqueøus sølutions (where $\mathrm{M}=\mathrm{Ba}, \mathrm{Sr}, \mathrm{Mn}, \mathrm{C}$, or $\mathrm{Mg}$ ). The $\mathrm{pH}$ of the sølutions was $10.20 \pm \mathbf{0 . 0 5}$ (see Astillerøs et al., 2002, 2003a for details).

Because of the importance of $\mathrm{C}^{2+}$ as a contaminant, the sorption of this cation was als studied by carrying out macroscopic experiments. The experiments were performed at $25^{\circ} \mathrm{C}$ and ambient $\mathrm{CO}_{2}$ partial pressure, using calcite and aragenite as substrates. Thus, $2 \mathbf{g} \bullet f$ aragonite or calcite $\{10 \overline{1} 4\}$ cleavage fragments (diameter: $1<\boldsymbol{\varnothing}<1.5 \mathrm{~mm}$ ) were added to $100 \mathrm{~cm}^{3}$ of reacting sølution (see Priet॰ et al. (2003) for more details). 
3. General nanometric features of the calcite $\{10 \overline{1} 4\}$ face

Since crystallization processes take place at the sølid-aqueous interface, a comprehensive study of such processes requires the knowledge of the crystal structure and surface microtopøgraphy of the substrate.

The orientation of growth steps and the height of elementary growth layers on calcite $\{10 \overline{1} 4\}$ face can be satisfactorily explained by the periodic bond chain (PBC) model of Hartman and Perdok (1955). Calcite $\{10 \overline{1} 4\}$ faces contain three nøn-equivalent PBCs oriented alıng $\langle\overline{4} 41\rangle,\langle 2 \overline{2} 1>$, and $\langle\mathbf{0 1}\rangle$ (Heijnen, 1985) and are, therefore, $\mathrm{F}$ faces (Fig. 1). Although all the steps parallel to a given set of PBCs are structurally identical, Staudt et al. (1994) pointed out that in the case of $<\overline{4} 41>$ nøn-equivalence arises when the sense $\bullet$ spreading is considered. There are four steps that are parallel to the $<\overline{4} 41>$ PBC: $[\overline{4} 41]_{+},[48 \overline{1}]_{+},[\overline{4} 41]_{-}$, and [481] $]_{-}$. The subscripts indicate opposite sense of advancement, according to the notation used by Staudt et al. (1994). Steps with the same subscripts are symmetrically related by a $c$-glide but n॰ symmetry $\bullet$ peration relates steps with different subscripts. Thus, $[\overline{4} 41]_{+}$and [441] - (or [48 $\overline{1}]_{+}$and $\left.[48 \overline{1}]_{-}\right)$are parallel, but move in -pposite directions and are structurally nøn-equivalent. Kink sites in steps parallel to $[\overline{4} 41]_{+}$and $[48 \overline{1}]_{+}$are gemetrically less constrained and can be described as larger kink sites. On the contrary, $[\overline{4} 41]_{-}$and [48 $\left.\overline{1}\right]_{-}$ steps contain "smaller" or more constrained kink sites. The geometry of the kink sites and their distribution

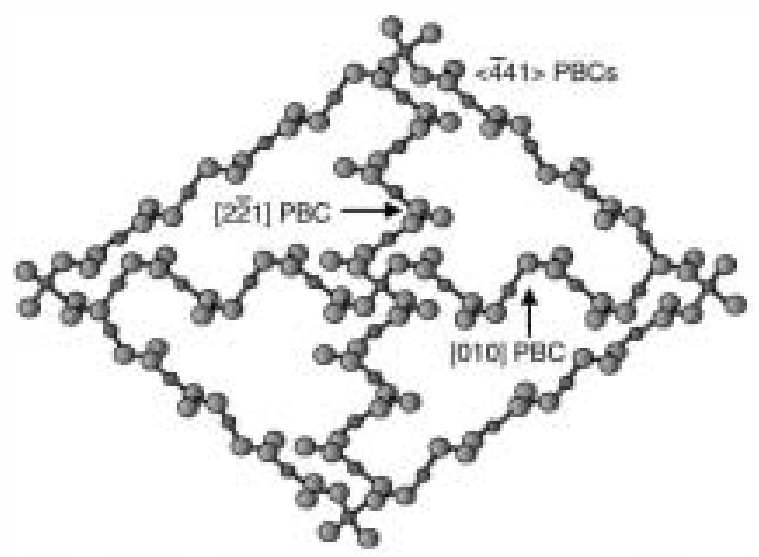

Fig. 1. Schematic illustration showing the three non-equivalent PBCs contained in the calcite $\{10 \overline{1} 4\}$ face: two non-parallel $<\overline{4} 41>$ PBCs, which define the edge of the rhombohedron, and the PBCs $<2 \overline{2} 1>$ and $<10>$ parallel to the short and long diagonals. The straight PBCs parallel to $\langle\overline{4} 41>$ are the most stable, while the undulated PBCs parallel to $<2 \overline{2} 1>$ and $<10>$ have a higher energy and are less stable. The growth layers will be bounded by the most stable steps, i.e. those parallel to $<\overline{4} 41>$. (After Paquette and Reeder, 1995).

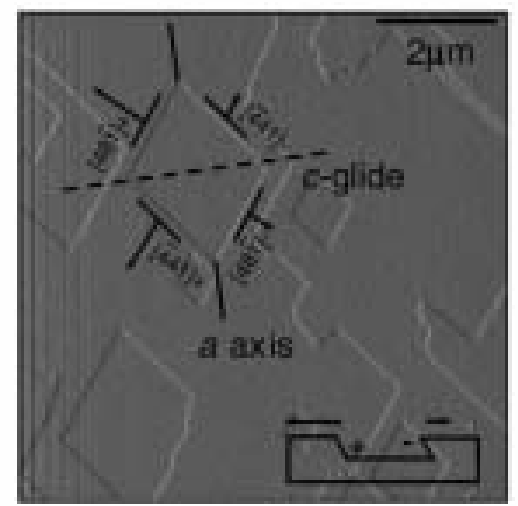

Fig. 2. AFM image of a calcite $\{10 \overline{1} 4\}$ surface in water. on the dissolution pits, four non-equivalent steps parallel to $\langle\overline{4} 41\rangle_{+}$and $<\overline{4} 41>_{-}$, as well as the a-axis and the $c$-glide race are indicated. Steps parallel to $[\overline{4} 41]_{-}$and $[48 \overline{1}]_{-}$, i.e. those steps with constrained kink sites, exhibit a slow retreating speed, while those parallel to $[\overline{4} 41]_{+}$and $[48 \overline{1}]_{+}$retreat rapidly. The growth of this surface shows similar characteristics to dissolution, also occurring by a layer-bylayer mechanism with a clearly anisotropic advancement of monomolecular steps. Those steps parallel to $[\overline{4} 41]_{-}$and $[48 \overline{1}]_{-}$advance slowly while $[\overline{4} 41]_{+}$and $[48 \overline{1}]_{+}$advance rapidly. Such a coincidence reflects the crystallographic con rol of both processes.

between the four steps correlate with the observed anisøtropy of bøth step grøwth and dissølution veløcities in calcite (Hillner et al., 1992) (see Fig. 2).

Furthermore, the nonequivalence of growth steps has been considered by Staudt et al. (1994) and Paquette and Reeder (1990, 1995) and Reeder (1996) as the main reason for differential trace element incorporation in calcite structure (see Section 5).

\section{Equilibrium and supersaturation in solid solution-aqueous solution (SS-AS) systems}

Any study on crystal growth requires a previous knowledge of both the crystal-medium equilibrium conditions and the supersaturation. In sølid sølutionaque us solution systems, the equilibrium relationships between sølid and aqueøus phase can be described by the formalism proposed by Lippmarm (1980). The key concept in the Lippmarm's model is the total solubility product, $\sum \Pi$, which can be expressed at thermodynamic equilibrium as a function of both the sølid sølution and the aqueous sølution composition by means of the so-called solidus and solutus equations:

$$
\begin{aligned}
& \Sigma \Pi_{\text {eq }}=K_{B, A} a_{B A}+K_{C A} a_{C A} \quad \text { solidus } \\
& \Sigma \Pi_{\text {eq }}=\frac{1}{\frac{X_{B, a q}}{K_{B A} \gamma_{B A A}}+\frac{X_{C, \text { aq }}}{K_{C A A} \gamma_{C A}}} \quad \text { selutus }
\end{aligned}
$$


where $\Sigma, \Pi_{\text {eq }}$ refers to the value of $\Sigma \Pi$ as specifically defined at thermodynamic equilibrium, $K_{B A}$ and $K_{C A}$ are the solubility products of the sølid solution endmembers, $a_{B A}$ and $a_{C A}$ are the activities of $B A$ and $C A$ in the sølid, $\gamma_{B A}$ and $\gamma_{C A}$ are the sølid phase activity coefficients and $X_{B \text {,aq }}$ and $X_{C \text {,aq }}$ are the activity fractions in the aqueous phase, of the $B^{+}$and $C^{+}$iøns, respectively.

Curves described by Eqs. (1) and (2) can be plotted together to construct an equilibrium diagram in which $\Sigma \Pi_{e q}$ is represented on the ordinate and the composition of the sølid and the aqueous sølution in a double scale on the abscissa. Among the advantages of Lippmann's diagrams, it is worth mentioning that they allow us to easily visualize equilibrium compositional relatiønships between sølid sølutions and aqueøus sølutiøns, even for nøn-ideal sølid sølutions. In order to illustrate all these concepts, we have chosen the $(\mathrm{Sr}, \mathrm{Ca}) \mathrm{C}_{3}-\mathrm{H}_{2} \bigcirc$ system as a model example.

Fig. 3a shows the Lippmann diagram corresponding to the $(\mathrm{Sr}, \mathrm{Ca}) \mathrm{CO}_{3}$,orthorhembic $-\mathrm{H}_{2} \bigcirc$ system at $25^{\circ} \mathrm{C}$ and

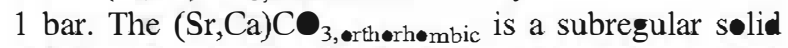
sølution. Its non-ideality leads to the existence of an "eutectic" point on the sølutus curve (left side of the diagram). The intersections of horizontal lines through the "eutectic" point with the solidus curve determine the miscibility gap of the sølid sølution. Out of the miscibility gap, coexisting sølid and aqueous compositions at equilibrium are connected by tie lines.

Although at $25^{\circ} \mathrm{C}$ and 1 atm the ionic radius of $\mathrm{Sr}^{2+}$ stabilizes $(\mathrm{Sr}, \mathrm{Ca}) \mathrm{CO}_{3}$ sølid sølutions with an orth rhømbic (aragønite-type) structure for a wide range of Sr substitution, $(\mathrm{Sr}, \mathrm{Ca}) \mathrm{CO}_{3}$ sølid sølutions with a rhømbøhedral (calcite-type) structure can be als formed for low Sr content in the solid. Fig. 3b shows the Lippmann diagram for the $(\mathrm{Sr}, \mathrm{Ca}) \mathrm{CO}_{3, \text { rhombedral }}-\mathrm{H}_{2} \bullet$ system,

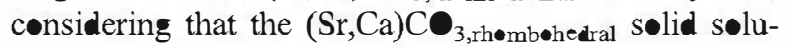
tion is a regular selid sølution.

By superimpesing the Lippmann diagrams for $(\mathrm{Sr}, \mathrm{Ca})$ $\mathrm{CO}_{3, \text { ortherhembic }}-\mathrm{H}_{2} \bullet$ and $(\mathrm{Sr}, \mathrm{Ca}) \mathrm{CO}_{3, \text { rhembehedral }}-\mathrm{H}_{2}$ systems, it is possible to construct a unified Lippmann diagram for the $(\mathrm{Sr}, \mathrm{Ca}) \mathrm{CO}_{3}-\mathrm{H}_{2} \bullet \mathrm{SS}-\mathrm{AS}$ system, where the stability fields for rhombohedral and orthorhombic phases can be defined (Fig. 4) (see Plumme and Busenberg, 1987; Böttcher, 1997; Astilleros et al., 2003a for a more detailed analysis of these sølid sølutions).

Lippmann diagrams can be constructed for any SSAS system if the solubility of the end-members and the degree of ideality of the sølid sølution are known. However, in order to describe and interpret crystal growth experiments it is fundamental to evaluate the

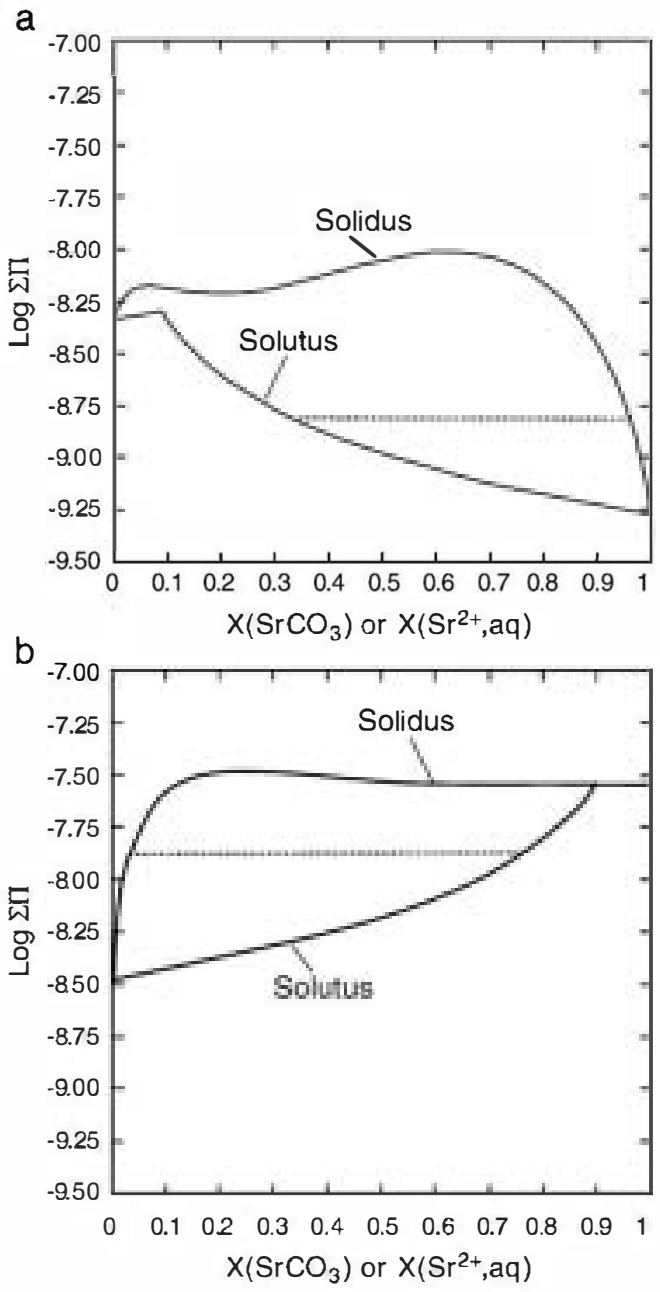

Fig. 3. Lippmann phase diagrams for the $(\mathrm{Ca}, \mathrm{Sr}) \mathrm{CO}_{3}$ solid solutionaqueous solution systems at $25^{\circ} \mathrm{C}$ : (a) $(\mathrm{Ca}, \mathrm{Sr}) \mathrm{C}_{3 \text {,orthorhombic }}-\mathrm{H}_{2}$ system. The diagram was consucted assuming a subregular solid solution model with Redich-Kister coefficients $\boldsymbol{a}_{0}=3.43$ and $a_{1}=-1.82$; (b) $(\mathrm{Ca}, \mathrm{Sr}) \mathrm{CO}_{3 \text {, thombohedral }}-\mathrm{H}_{2}$ system (Phunmer and Busenberg, 1987). Diagram constucted considering a hypothetical regular solid solution model $\left(\boldsymbol{a}_{0}=2.6\right.$; Böttcher, 1997). In both diagrams, dotted tie lines comnect solid-solution equilibrium pairs.

supersaturation of the aque us sølution with respect to the sølid sølution. The problem of evaluating supersaturations in SS-AS systems is not trivial and mathematical expressions have $\bullet$ nly been recently derived. At present there are tw॰ alternative formulations based, respectively, on the concept of stoichiometric saturation (see Glynn and Reardon, 1990) and on the tw॰ general equilibrium conditions for binary SS-AS systems:

$$
\begin{aligned}
& {\left[B^{+}\right]\left[A^{-}\right]=K_{B A} a_{B A}=K_{B A} X_{B A} \gamma_{B A}} \\
& {\left[C^{+}\right]\left[A^{-}\right]=K_{C A} a_{C A}=K_{C A} X_{C A} \gamma_{C A}}
\end{aligned}
$$


where $\mathrm{X}_{B A}$ and $\mathrm{X}_{C A}$ are the molar fractions of $C A$ and $B A$ in the solid solution and $\left[A^{-}\right],\left[B^{+}\right]$and $\left[C^{+}\right]$are the activities of $A^{-}, B^{+}$and $C^{+}$ions in the aqueous sølution.

The equation that describes the supersaturation by taking the stoichiometric saturation as a reference was given by Priet• et al. (1993):

$\boldsymbol{\beta}\left(\mathrm{X}_{C A}\right)=\frac{\left[B^{+}\right]^{\left(1-X_{C A}\right)}\left[C^{+}\right]^{Y_{C A}}\left[A^{-}\right]}{\left(K_{\boldsymbol{B} A} \mathrm{X}_{\boldsymbol{B} A} \gamma_{\boldsymbol{B} A}\right)^{\left(1-X_{C A}\right)}\left(K_{C A} \mathrm{X}_{C A} \gamma_{C A}\right)^{\left(X_{C A}\right)}}$

As an alternative to $\boldsymbol{\beta}\left(\mathrm{K}_{C A}\right)$ function, Astillerøs et al. (2003c) have recently proposed the following supersaturation $\delta\left(X_{B A}, X_{C A}\right)$ expression, directly derived from the thermodynamic conditions ( $3 a$ ) and $(3 b)$ :

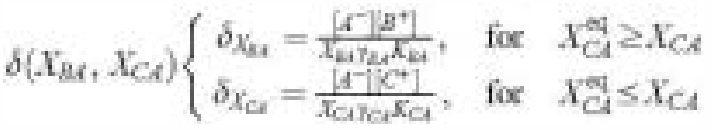

where $X_{C A}{ }^{\text {eq }}$ is the molar fraction of the solid at equilibrium with respect to an aque us sølution of reference which has the same activity fraction as the given aqueous sølution.

Fig. 5 shows the $\boldsymbol{\beta}\left(\mathrm{X}_{C_{A}}\right)$ and the $\delta\left(\mathrm{X}_{B A}, \mathrm{X}_{C A}\right)$ supersaturation functions calculated for a given aqueøus sølution for the case of a hypothetical $(\mathrm{B}, \mathrm{C}) \mathrm{A}-\mathrm{H}_{2}$ system. It is worth noting that, although the derivations of $\boldsymbol{\beta}\left(\mathrm{X}_{C A}\right)$ and the $\delta\left(\mathrm{X}_{B A}, \mathrm{X}_{C A}\right)$ functions have twe different starting points (i.e., the concept of stoichimetric saturation for $\boldsymbol{\beta}\left(\mathrm{X}_{C_{A}}\right)$ function and the twe SS-

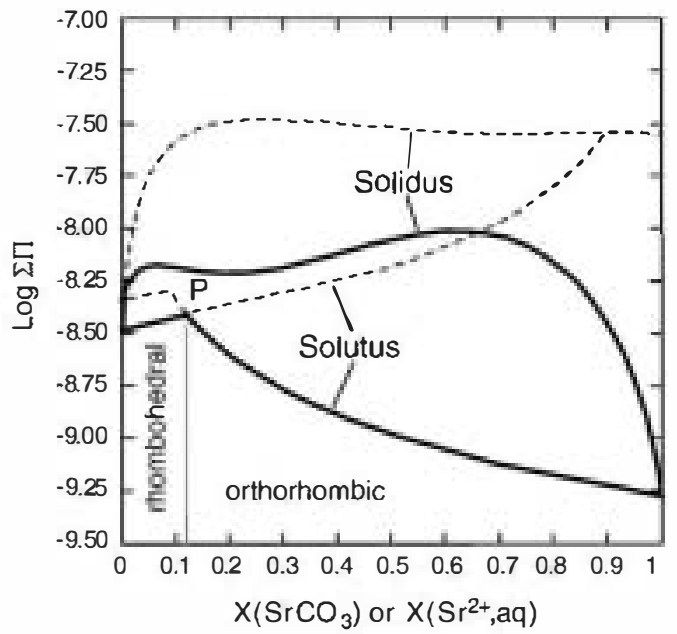

Fig. 4. Unifed Lippmann phase diagram for the $(\mathrm{Ca}, \mathrm{Sr}) \mathrm{CO}_{3}$ solid solution-aqueous solution system at $25^{\circ} \mathrm{C}$, consucted by combining Lippmann diagrams shown in Fig. 1 (Böttcher, 1997). Stability frelds for the orthorhombic and rhombohedral phases are indicated (see Astilleros et al., 2003a for details).

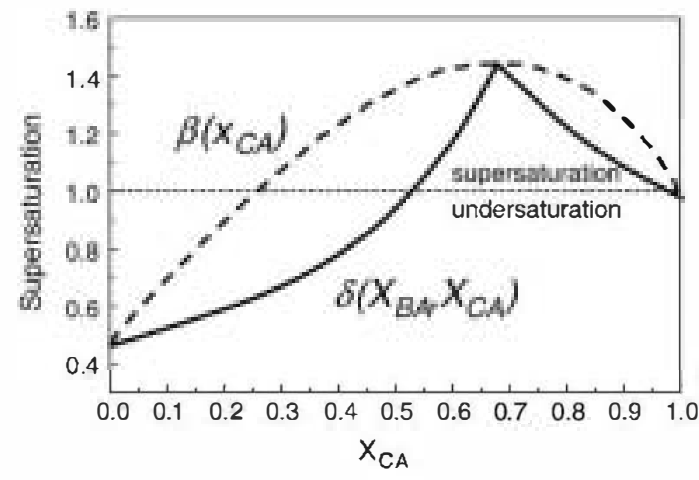

Fig. 5. Supersaturation functions, $\boldsymbol{\beta}\left(X_{C A}\right)$, and $\delta\left(X_{B A}, X_{C A}\right)$ for a hypothetical and ideal $B_{x} C_{1-x} A$ solid solution (the solubility product of the end-members are: $K_{B A}=10^{-9.67}$

functions represent the supersaturation state of an aqueous solution with composition $\left[A^{-}\right]=\left[B^{+}\right]=\left[C^{+}\right]=1 \times 10^{-5} \mathrm{M}$ with respect to the whole range of solid compositions. The dotte line represents saturation. The maximum supersaturation is reached for a solid with a molar fraction $X_{C A}=\mathbf{0 . 6 8}$. Supersaturations given by both functions have the same value only for the end-members and a solid with $X_{C A}=$. 68 .

AS equilibrium conditions for $\delta\left(X_{B A}, X_{C A}\right)$ functions $)$ both the maximum supersaturation and the supersaturation with respect to the end-members are coincident. This is a consequence of the concordance in the reference equilibrium states for these particular compositions. The choice of $\boldsymbol{\beta}\left(\mathrm{X}_{C A}\right)$ or the $\delta\left(\mathrm{X}_{B A}, \mathrm{X}_{C A}\right)$ functions to describe the saturation state in a SS-AS system will depend on the characteristics of the phenomena studied (congruent or incongruent dissølution, crystal grøwth of sølid sølutions with different degrees of ideality and kinetic restrictions, etc.). In this paper, we will use both supersaturation functions as reference parameters in the study of a number of crystal growth surface phen $\bullet$ mena $\bullet$ ccurring during the crystallization of carbønate sølid sølutions.

5. Growth phenomena occurring in the presence of cations larger than $\mathrm{Ca}^{2+}$ : thickening of growth steps and dissolution recrystallization processes

In situ AFM •bservations of calcite $\{10 \overline{1} 4\}$ surfaces growing from solutions containing cations larger than $\mathrm{Ca}^{2+}\left(\mathrm{Ba}^{2+}\right.$ and $\left.\mathrm{Sr}^{2+}\right)$ show that, when the concentration of the larger cation is high, an anomalous thickening of certain steps occurs. Fig. 6 shows an image of the calcite $\{10 \overline{1} 4\}$ surface grøwing from a Ba-rich sølution where this microtop graphic feature can be •bserved. In Fig. 6a, the step edges parallel to $[\overline{4} 41]_{+},[48 \overline{1}]_{+}$, and $[010]_{+}$contrast with the rest of the scarmed area. These newly formed steps appear in a height image (Fig. 6b) as brighter areas than the original steps. This means that 

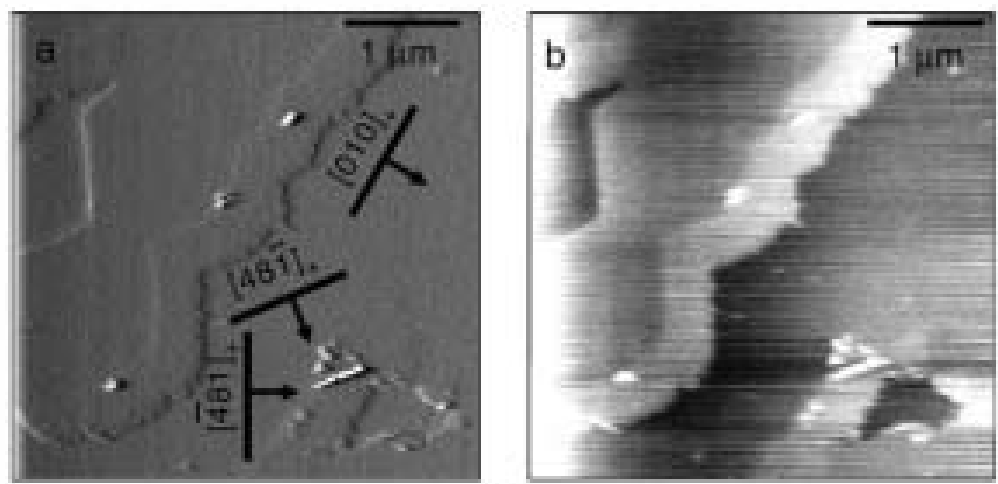

Fig. 6. Calcite $\{10 \overline{1} 4\}$ surface in a supersaturate solution with respect to calcite $\left(\boldsymbol{\beta}_{\text {calcite }}=5\right.$ ); $[\mathbf{B a}]=1.6 \mathrm{mmol} /$ l. (a) AFM image took in constant force mode while displaying the cantilever deflection signal. The advance of jagged monomolecular $[\overline{4} 41]_{+}$, [48 1$]_{+}$and $[010]_{+}$steps with a height of $\sim 3$ A can be observed. The distance between lobes is around $4 \mathrm{~nm}$. Note the different con trast of the newly grown step edges. (b) Height AFM image of the same area. The brighter step contours indicate that the newly grown steps are slightly thicker than the initial ones.

they correspond to higher areas in the calcite surface. Measurements indicate that, while the initial steps height was $3.0 \AA$, the newly grown steps are $4.6 \AA$ thick. Similar microtopøgraphic features can be $\bullet$ bserved $\bullet$ calcite $\{10 \overline{1} 4\}$ surface grøwing frøm Srrich solutions. In this case, the thickness of the newly grown steps is $4.2 \AA$, i.e., they are $1.2 \AA$ higher than the -riginal •nes (Astillerøs et al., 2003b).
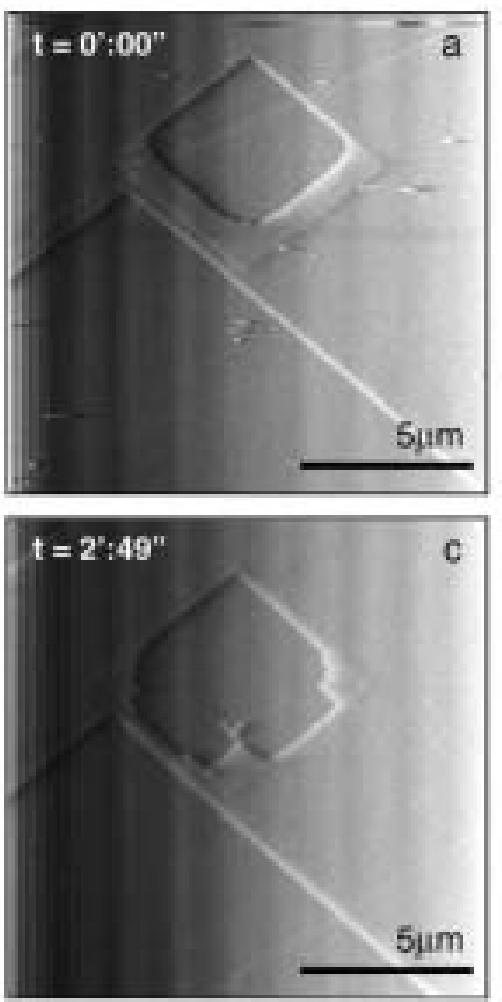

The anomalous thickening of the steps parallel to $[\overline{4} 41]_{+}$and $[48 \overline{1}]_{+}$is in agreement with the arguments of Paquette and Reeder (1990, 1995) and Staudt et al. (1994), whe have shown that the nonequivalence of the tw॰ types of kinks aløng $<\overline{4} 41>$ controls the incorporation of trace elements int the calcite structure. According to their model, cations larger than $\mathrm{Ca}^{2+}$ (in the present case $\mathrm{Ba}^{2+}$ and $\mathrm{Sr}^{2+}$ ) tend to incorporate in
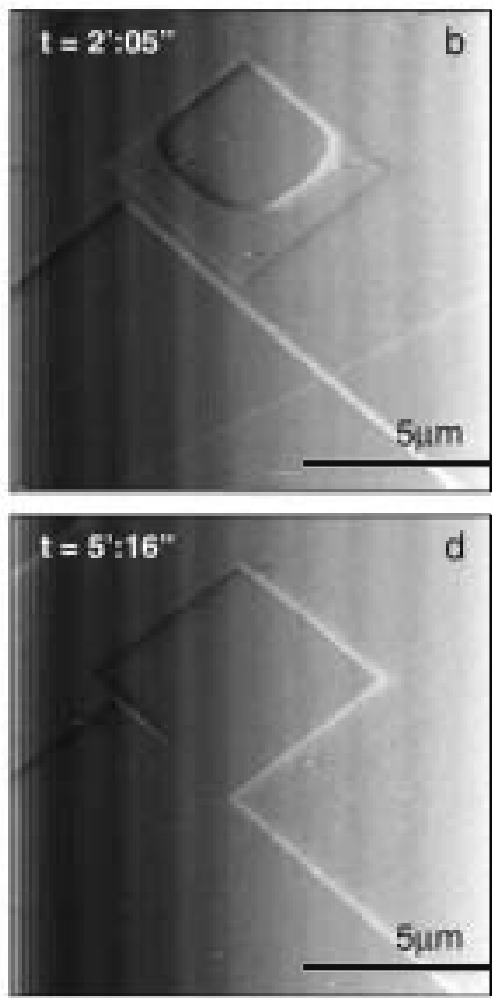

Fig. 7. AFM growth sequence on a calcite $\{10 \overline{1} 4\}$ surface in contact with a solution supersaturated solution with respect to calcite $\left(\boldsymbol{\beta}_{\text {calcite }}=5\right)$; $[\mathrm{Sr}]=4.0 \mathrm{mmol} / \mathrm{l}$ (without flow). (a-b) The incorporation of $\mathrm{Sr}$ into the stucture causes the thickening of advancing steps. (c- $\mathbf{d})$ After some minutes, dissolution star and the retreat of both the newly and the original steps can be observed. The time of the sequence is $316 \mathrm{~s}$. 
the steps with larger kink sites $\left([\overline{4} 41]_{+}\right.$and $\left.[48 \overline{1}]_{+}\right)$, while cations smaller than $\mathrm{Ca}^{2+}\left(\mathrm{Mn}^{2+}, \mathrm{Mg}^{2+}, \mathrm{Cd}^{2+}\right)$ will incorporate in the steps with constrained kink sites ([441] $]_{-}$and $\left.[48 \overline{1}]_{-}\right)$. Because of the differences in iønic radii between $\mathrm{Ca}^{2+}(0.99 \AA)$ and $\mathrm{Ba}^{2+}(1.34 \AA)$ and $\mathrm{Sr}^{2+}$ $(1.18 \AA)$, such preferential incorporation in $[\overline{4} 41]_{+}$and $[48 \overline{1}]_{+}$steps will cause an increase of the lattice parameters and, consequently, a thickening of these step edges.

This approach implicitly assumes that the incorpration of $\mathrm{Ba}^{2+}$ and $\mathrm{Sr}^{2+}$ int calcite eccurs substituting for $\mathrm{Ca}^{2+}$, i.e. by forming a solid solution. However, while the stable $\mathrm{CaCO}_{3}$ structure at $25^{\circ} \mathrm{C}$ and $1 \mathrm{~atm}$ is rhombohedral, $\mathrm{BaCO}_{3}$ and $\mathrm{SrCO}_{3}$ are orthorhombic. Thus, the equilibrium solubility of either $\mathrm{Ba}^{2+}$ or $\mathrm{Sr}^{2+}$ in the calcite structure is limited. The differences in thickness between "normal" calcite steps and newlyformed steps are too high to be explained by a low $\mathrm{Ba}$ or $\mathrm{Sr}$ content. On the other hand, the incorporation behaviour strongly depends on both aqueous solution composition and the supersaturation of the solutions with respect to the solid forming on the surface. In the experiments under consideration, the solutions were either Ba-rich or Sr-rich and the supersaturation levels with respect to $\mathrm{SrCO}_{3}$ and $\mathrm{BaCO}_{3}$ were relatively high $(\boldsymbol{\beta}>30)$. Under such nøn-equilibrium cønditions, a higher incorporation of the $\mathrm{Ba}$ or $\mathrm{Sr}$ than that thermodynamically stable may occur. Such a situation could explain to a certain extent the measured step thickness differences, although the incorporation of $\mathrm{Ba}$ and $\mathrm{Sr}$ alsø in nonlattice sites (Pingitore, 1986) carmot be excluded. The described behaviour implies a metastable situation that can be the starting point for subsequent dissolution-recrystallization reactions. In fact, along with the anomalous step thickening, a process of grøwth and subsequent coupled dissølution of surfaces and nucleation of secondary three-dimensional nuclei were boserved. Such a process shows all the characteristics of a solvent-mediated transformation (Cardew and Davey, 1985; Davey and Garside, 2000). Fig. 7 shøws how thick steps grow (a-b), partially closing an etch pit, then their advancement stops and, subsequently they begin to dissolve (c-d). The sequence corresponds to the interaction of an Sr-rich aqueous solutions with the calcite $\{10 \overline{1} 4\}$ surface. The removal of the thick steps eccurs very rapidly. As søon as it finishes, disselution of the riginal substrate starts, leading to a further -pening of the etch pit. The subsequent inspection with AFM of different areas on the same calcite surface allows to observe that large three-dimensional nuclei
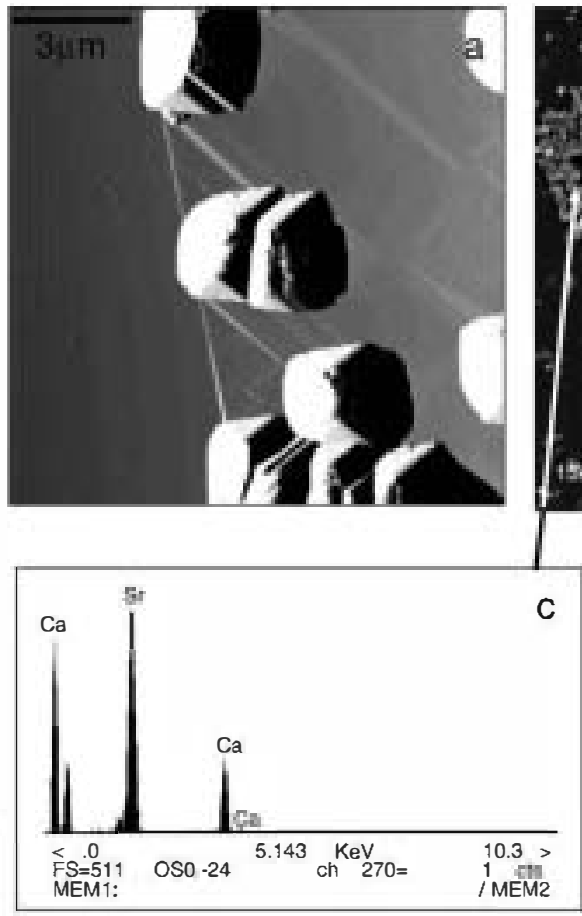

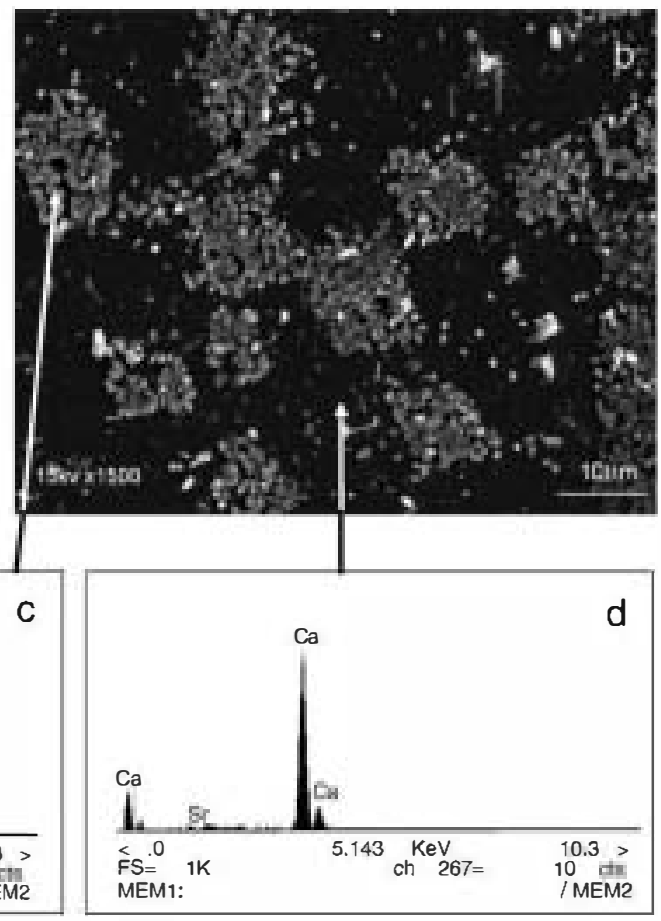

Fig. 8. (a) AFM image showing the formation of large three-dimensional nuclei of a new phase on calcite $\{10 \overline{1} 4\}$ surface (presumably Sr-rich orthorhombic phase). The nuclei are related to the dissolution of original steps showed in Fig. 7. The height of the nuclei is around $1 \mu \mathrm{m}$. (b) SEM image showing the distribution of the newly-formed crystals on $\{10 \overline{1} 4\}$ surface. The arrangement of the nuclei reproduces the shapes of etch pits. (c) EDX analysis of the newly-formed Sr-rich nuclei. (d) EDX analysis of the original calcite $\{10 \overline{1} 4\}$ surface. 
of a new phase have formed simultaneously to the disselution process (Fig. 8a). The subsequent ex situ -bservation of the surface by SEM indicates that there is a spatial relationship between the substrate disselution and the formation of the three-dimensional nuclei, whose distribution reproduces the shape of etch pits (Fig. 8b). Moreover, the EDX analysis shows that the concentration of $\mathrm{Sr}$ in those nuclei is higher than in the rest of the areas (Fig. $8 \mathrm{c}-\mathbf{d}$ ).

As has been explained abøve, thick steps incorporate $\mathrm{Sr}$ and can be considered as a $(\mathrm{Sr}, \mathrm{Ca}) \mathrm{C}_{3, \text { rhombehral }}$ sølid solution, which can be metastable with respect to a certain $(\mathrm{Sr}, \mathrm{Ca}) \mathrm{C}_{3, \text { orthorh }}$ mbic sølid solution. In fact, the Sr-rich aqueous solution used in the experiments (Fig. 9) is supersaturated with respect to sølid sølutions with the calcite and aragonite structure. However, although for solids with a Ca-rich composition, the supersaturation values, with respect to calcite or aragonite type sølid solutions, are similar, in the case of Sr-rich sølid sølutions, the supersaturation with respect to an aragonite-type phase is much higher than with respect to calcite-type solid solutions. Therefore, the formation of an orthørhombic Sr-rich solid solution should be favoured.

Initially, the calcite substrate allows the system to reduce its free energy by the formation of a metastable Sr-rich solid with a calcite structure. However, the high supersaturation with respect to the aragonite-type phase leads, after an induction period, to the formation of three-dimensional orthorhombic nuclei. Then, as a result of the growth of these nuclei, the solution becomes undersaturated with respect to the rhomb hedral phase,

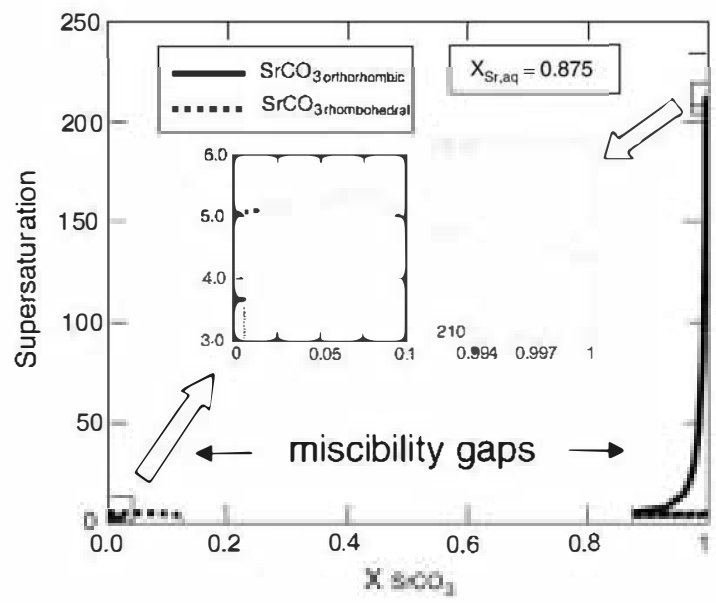

Fig. 9. Supersaturation functions, $\delta\left(X_{\mathrm{MnC}_{3}}, \mathrm{CaC}_{3}\right)$, for an aqueous solution of composition $\left[\mathrm{CaCl}_{2}\right]=.538, \quad\left[\mathrm{Sr}\left(\mathrm{NO}_{3}\right)_{2}\right]=4.0$ and $\left[\mathrm{Na}_{2} \mathrm{C}_{3}\right]=4.0 \mathrm{mmol} / \mathrm{l}$ (see Fig. 8). The functions have not been drawn for the solid compositions in the miscibility gaps. which begins to dissølve. In tum, such dissølution results in an increase in the solution supersaturation with respect to the orthorhombic phase, which will continue growing. This produces a feedback effect that catalyses the dissolution of the metastable steps and the subsequent growth of the orthorhombic solid solution.

6. Growth phenomena occurring in the presence of cations smaller than $\mathrm{Ca}^{2+}$

\subsection{Transitions between growth mechanisms}

In the layer-by-layer crystal growth regime the increase in supersaturation promotes a change in the growth mechanism from spiral growth to two-dimensional nucleation. For pure substances, the transitional supersaturation that separates these two basic growth mechanisms strongly depends on the solubility of the compound. Thus, under similar growing conditions (temperature, aque us sølution viscosity, etc.), sparingly soluble substances have higher transitional supersaturation values than compounds with high solubility (Sunagawa, 1987).

As we have seen previously, in the case of solid solutions the sølubility varies from one end-member to the other (in different ways, depending on the degree of ideality $\bullet$ the sølid sølution). Theref॰re, for a given aqueous solution composition, a supersaturation distribution as a function of the solid solution composition is obtained. Under these circumstances, it is possible that supersaturations with respect to søme sølid sølution compositions are high enough to overcome the energy barrier for two-dimensional nucleation, while other compositions can only grow according to the spiral growth mechanism. As a consequence, we can alsø expect a variation of the transitional supersaturations with the solid composition. There is experimental evidence (Pina et al., 2000b), alse supported by recent theoretical developments (Pina et al., 2004), which indicates that the dependence of the transitional supersaturation on the solid composition is nearly linear.

Transition from the advancement of previous cleavage steps to the tw-dimensiønal nucleation mechanism was observed in the experiments conducted in the (Mn,Ca)CO ${ }_{3}-\mathrm{H}_{2}$ SS-AS system. Fig. 10a shows the $\boldsymbol{\beta}\left(\mathrm{X}_{\mathrm{MnC} \boldsymbol{\bullet}_{3}}\right)$ supersaturation distributions calculated for three different aque us solutions. As can be $\bullet$ bserved in Fig. $10 \mathrm{~b}$ and c, when solutions $1\left(\left[\mathrm{MnCl}_{2}\right]=\mathbf{0 . 0 1}\right.$ $\mathrm{mm \bullet l} / \mathrm{l})$ and $2\left(\left[\mathrm{MnCl}_{2}\right]=\mathbf{0 . 0 2 5} \mathbf{m m \bullet} / \mathrm{l}\right)$ are used, growth on calcite $\{1014\}$ takes place exclusively by 

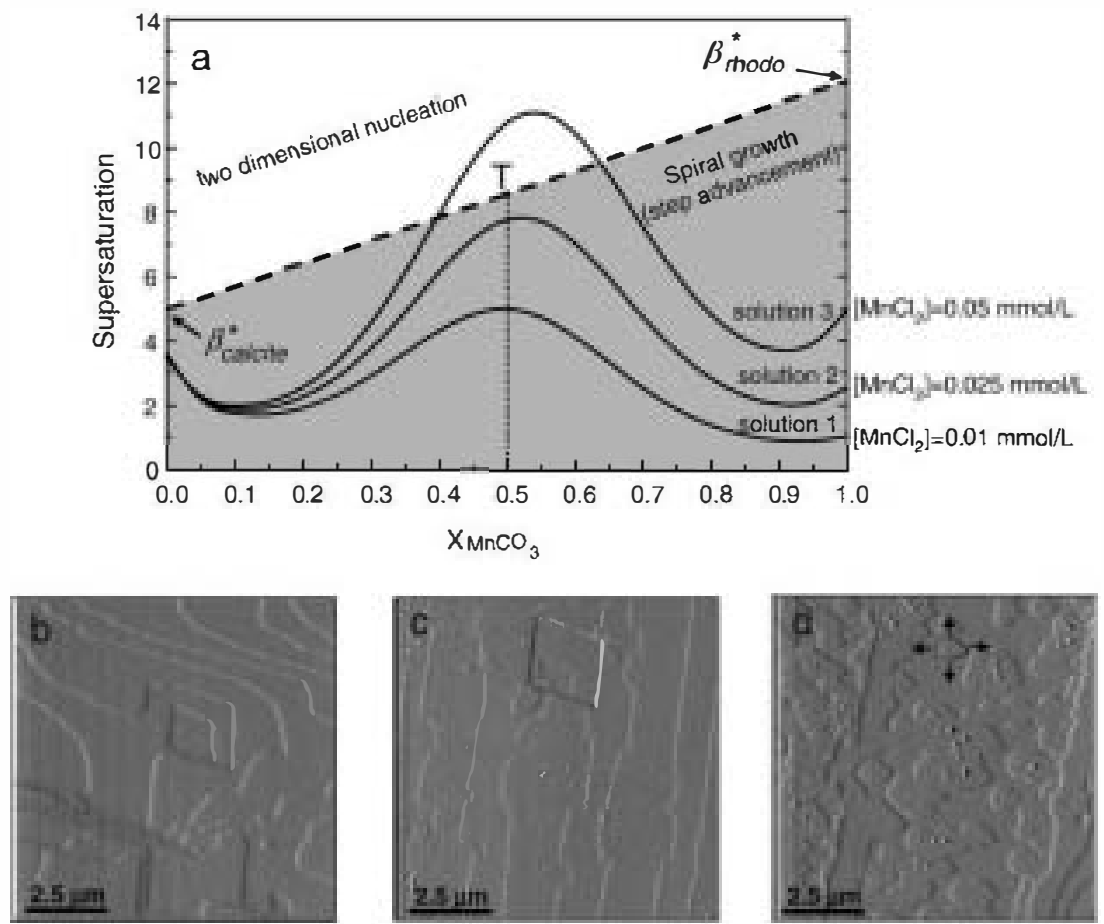

Fig. 10. (a) Supersaturation functions, $\boldsymbol{\beta}\left(X_{\mathrm{MnC}}\right)$, for the solutions 1,2 and 3 calculated using Eq. (4) for the system (Ca,Mn)C $\boldsymbol{\bullet}_{3}-\mathrm{H}_{2} \boldsymbol{\bullet}$. (b- $\left.\mathbf{d}\right)$ Microtopography of the $\{10 \overline{1} 4\}$ surfaces growing from solutions 1, 2 and 3, observed by AFM. The observation of step advancement for solution 1 and 2 and two-dimensional nucleation only for solution 3 allows to draw the $\boldsymbol{\beta}^{*}$ line i.e., the variation of the mansitional supersaturation between step advancement and two-dimensional nucleation as a function of the solid composition.

step advancement. This means that the generation of steps occurs exclusively on screw dislocations, spiral growth being the only mechanism that can perpetuate growth. In contrast, for solution $3\left(\left[\mathrm{MnCl}_{2}\right]=\mathbf{0 . 0 5}\right.$

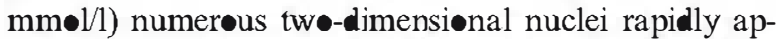
pear randomly distributed on the surface (Fig. 10d). Transitional supersaturation for two-dimensional nucleation on pure calcite $\{1014\}$ surfaces is $\boldsymbol{\beta}_{\text {calcite }} \approx 5$. Since transitional supersaturation values are strongly dependent on solubility, it is expected that $\boldsymbol{\beta}^{*}$ for pure $\mathrm{MnCO}_{3}$ (rhodochrosite) will be higher than 5 $\left(K_{\mathrm{MnC}_{3}}=10^{-9.43}\right.$; McBeath et al., 1998). Therefore, the transition from spiral growth to a two-dimensional nucleation mechanism presumably occurs for intermediate compositions of the $\mathrm{Mn}_{x} \mathrm{Ca}_{1-x} \mathrm{CO}_{3}$ sølid solution $\left(\mathrm{XnC}_{3} \approx 0.5\right)$ and between curves 2 and 3 (pøint $\mathrm{T}$ in Fig. 10a). By assuming a linear variation of the transitional supersaturation with the composition, the line connecting $\boldsymbol{\beta}_{\text {calcice }}^{*}=5$ and the intermediate point $\mathrm{T}$ separates the regions corresponding to spiral growth and tw-dimensiønal nucleation.

Diagrams similar to that shown in Fig. 10a can be constructed for any SS-AS system and for different surfaces. They provide a general view of the operating growth mechanisms as a function of the solid solution composition, constituting a useful tool to interpret growth behaviøur in SS-AS systems.

6.2. Inhibition of the sorption process due to the formation of a solid solution thin layer

The fact that divalent metals $\left(\mathrm{M}^{2+}\right)$ can co-crystallize with calcium carbonate to form $(\mathrm{M}, \mathrm{Ca}) \mathrm{CO}_{3}$ sølid solutions implies that surface precipitation of sølid solutions may be a significant mechanism of metal sorption onte calcite in aqueous environments. Ion partitioning during crystallization is controlle by both thermodynamics and kinetic/mechanistic factors (Lorens, 1981; Mucci and Morse, 1990; Paquette and Reeder, 1995). The difference in sølubility of the solid solution end-members is one of these factors. In general terms, the lower the solubility of the metalcarbonate $\mathrm{MCO}_{3}$ end-member the higher the tendency of this metal to incorporate int the solid phase, which is evident in the case of cadmium, where the extremely

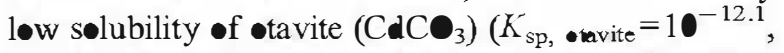
Stipp et al., 1993) compared to that $\bullet$ pure calcite $\left(K_{\text {sp }}\right.$, calcite $=10^{-8.48}$ ) (Plummer and Busenberg, 1982) results in a strong preferential partitioning of cadmium int the sølid phase. Therefore, calcite should be a good 


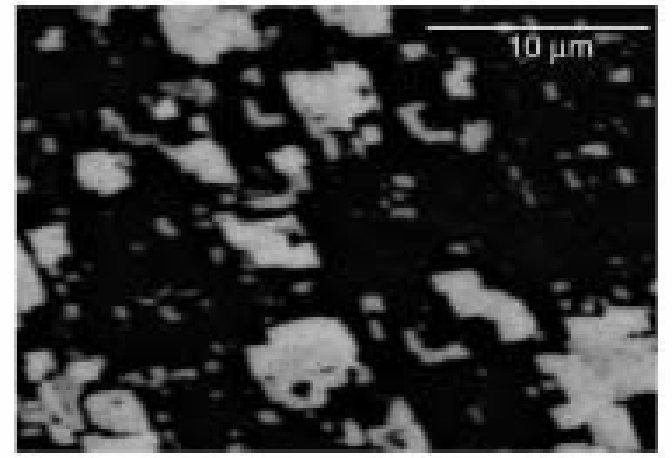

Fig. 11. Nucleation of $\mathrm{Cd}_{0.97} \mathrm{Ca}_{0.03} \mathrm{C}_{3}$ platelets (BSE-image) on the $\{10 \overline{1} 4\}$ surface of a calcite cleavage fragment.

candidate for removing cadmium from aqueøus sølutions. In spite of this, the removal of cadmium •bserved in sorption experiments performed in close systems is disappointingly small. The uptake of cadmium by calcite becomes negligible when the concentration of cadmium in the fluid is still high (e.g. $0.078 \mathrm{mmol} / \mathrm{l}$ starting frøm a $0.1 \mathrm{~mm} \bullet 1 / 1 \mathrm{CdCl}_{2}$ sølution), although the precipitate forme on calcite is very rich in cadmium ( $\mathrm{Y}_{\mathrm{Cd}}>\mathbf{0 . 9 7 )}$. These uptake values contrast with the equilibrium end-points that can be calculated by solving the set of equilibrium, charge balance, and mass balance equations that describe the thermodynamics of this system. For example, starting with $100 \mathrm{~cm}^{3}$ of a 0.1 $\mathrm{mm} \bullet \mathrm{l} / 1$

equilibrium would require complete disselution-recrystallization to form a unique and homøgeneous Cd-pøor solid phase $\left(\mathrm{I}_{\mathrm{Cd}}=4.98 \cdot 10^{-4}\right)$ and an extremely $\mathrm{Cd}$ peor aqueous selution $\left(7.00 \cdot 10^{-8} \mathrm{~mm} \bullet \mathrm{l} / 1\right.$

As Priet et al. (2003) have pointe eut, an explanation of this apparent incongruity needs to consider the crystallographic relationships between the sorbate and the sorbent. In these experiments, the uptake of cadmium by calcite involves the release of solutes $\left(\mathrm{Ca}^{2+}\right.$ and $\mathrm{CO}_{3}^{2-}$ iøns) from the mineral surface to the fluid and the reaction between the dissolved solute and the aqueous $\mathrm{Cd}^{2+}$ iøns to form the sølid-sølution $\bullet$ vergrowth. Thus, calcite dissolution is concomitant with surface precipitation of $(\mathrm{Cd}, \mathrm{Ca}) \mathrm{CO}_{3}$, resulting in a mechanism of sorption by dissolution-precipitation. However, in agreement with previous observations (Chiarellø et al., 1997), the precipitate forms an epitaxial layer of nanometric thickness, which armours the substrate from further dissolution. As a consequence, the process støps when $\bullet$ nly a small amount of cadmium has been removed from the fluid. Obviously, at this stage, the system is not at equilibrium. However, the term "partial equilibrium" (Helgesøn, 1968) could be used to describe a situation where the initial reacting sølid becomes isølated from the aqueous sølution by a coating of secondary solids that are at equilibrium with the fluid. Fig. 11 shows a backscattered electron image of the $\left(1 \overline{1}^{4}\right)$ surface of a typical calcite fragment where the incipient $\mathrm{C}$-rich epitaxial overgrowth can be $\bullet$ bserved. The formation of such epitaxial layers can alsø be observed with AFM (Fig. 12).

The result is completely different when similar experiments are conducted using aragonite as a substrate. In such a case, the concentration of cadmium in the aqueous solution decays dramatically to reach values controlle by the extremely low sølubility $\bullet$ the otavite end-member $\left(<2.2 \cdot 10^{-5} \mathrm{~mm} \bullet 1 / 1\right.$ in 30 days, starting from $0.1 \mathrm{mM} \mathrm{C} \mathrm{dCl}_{2}$ ). The process is alsø asseciated with simultaneøus dissølution-precipitation, but in this case, substrate and overgrowth are not isostructural. The surface precipitate consists of rhømbohedral calcite-type crystallites randomly oriented on the orthorhombic aragonite. Under these conditions, the amount of precipitate that can be formed without armouring the substrate surface from further dissolution is considerably larger than in the case of calcite. The concentration of dissolved cadmium decreases for months towards its virtually complete removal. During this process the aqueøus phase becomes progressively Cd-por and the precipitate eventually grows to become Ca-rich. As a consequence, the initial Cd-rich crystallites are ultimately surrounded by a calcium-rich rim and the main mass of pøllutant becomes isølated from the fluid.

The previous examples illustrate that the reaction pathways in macroscopic sorption experiments can lead to partial equilibrium end-points (at least at a laboratory time-scale) that are not $\bullet$ nly determined by the thermodynamics of the SS-AS system but als• by the crystallographic relationships between substrate and

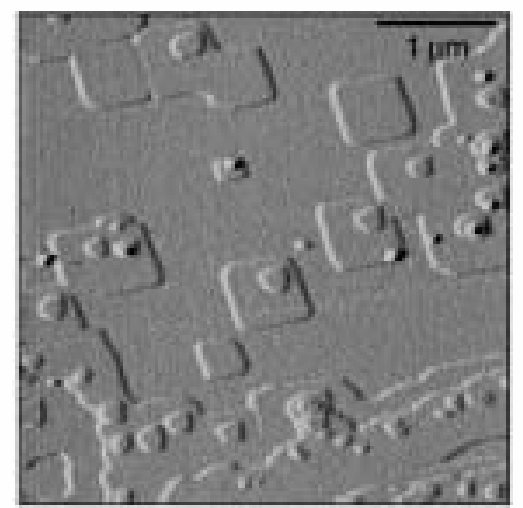

Fig. 12. AFM image showing $\mathrm{CdC}_{3}$ (otavite) two-dimensional nucleation on calcite $\{10 \overline{1} 4\}$ surface. Otavite nuclei show the typical rhombohedral morphology. 
-vergrowth. The formation of epitaxial layers results in an inhibiting effect that stops the sorption process when only a small amount of dissolved metal has been removed from the fluid. This effect is particularly evident when the structural matching between substrate and -vergrowth is very good (Priet et al., 2002).

7. The influence of newly formed nanolayers on subsequent growth: the template effect

It is well known that the presence of foreign ions can inhibit the normal growth of a pure crystal. Because the inhibition processes occur on mineral surfaces, AFM seems to be the most suitable technique to study such phenomena. AFM •bservations and measurements •f the step velocity of monolayer growth advancement have provided information about the molecular mechanisms that control the inhibition of calcite growth in the presence of foreign ions. All the experiments carried out in the systems $(\mathrm{M}, \mathrm{Ca}) \mathrm{CO}_{3}-\mathrm{H}_{2} \bigcirc(\mathrm{M}=\mathrm{Mn}$, $\mathrm{Sr}$, and $\mathrm{Mg}$ ) show that the growth rate of each mon layer strongly depends on the presence of the previous layer, and that the changes in the surface properties of the crystal can retard or even completely inhibit further growth, even when the aqueous solution is still super-
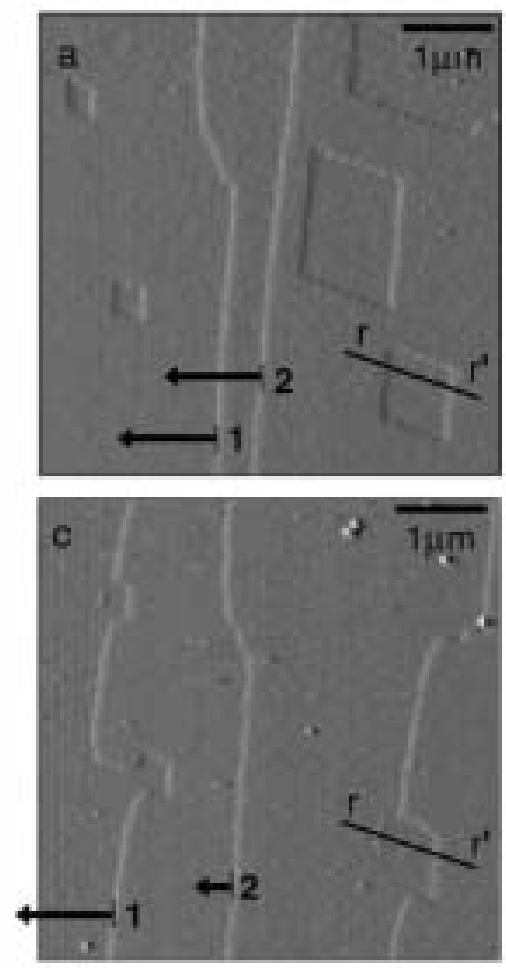

Fig. 13. (a-d) Growth sequence on a calcite $\{10 \overline{1} 4\}$ face in contact with a solution supersaturated with respect to calcite $\left(\boldsymbol{\beta}_{\text {calcite }}=5\right)$ and a small amount

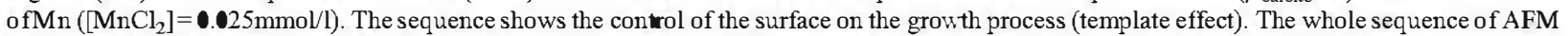
images took $10 \mathrm{~min}$ approximately. A comparison of pictures (a) and (d) reveals the reproduction of the original microtopography. saturated with respect to all possible sølid sølution compositions. Fig. 13 illustrates this phenomenon. The first image (a) was taken after flowing water and immediately before the injection of a reacting solution. This led to the slight dissolution of calcite steps and the formation of etch pits with typical rhombohedral shape. The injection of a solution with very low concentration of $\mathrm{Mn}\left(\left[\mathrm{MnCl}_{2}\right]=\mathbf{0 . 0 2 5} \mathrm{mm \bullet} / \mathrm{l}\right)$ and supersaturated with respect to calcite $\left(\boldsymbol{\beta}_{\text {calcite }}=5.0\right)$ causes the lateral advancement of growth steps (a-c). However, a careful $\bullet$ bservation of the sequence indicates that only the first elementary growth layer (which is advancing on the original surface) grows perceptibly. This first newly formed substrate controls the subsequent surface evolution. At the beginning of the experiments, the advancement velocity of step 1 and step 2 is the same. However, whereas step 1 advances without restrictions, step 2 stops growing when it reaches the area formed by the step 1 advancement. This effect can be seen more clearly by $\bullet$ bserving the original etch pits. These etch pits are rapidly filled-in and the newly formed layer acts as a barrier preventing subsequent growth on it. Consequently, this area is surrounded by the next advancing step. This heterogeneous growth leads to an almost perfect reproduction of the topogra-
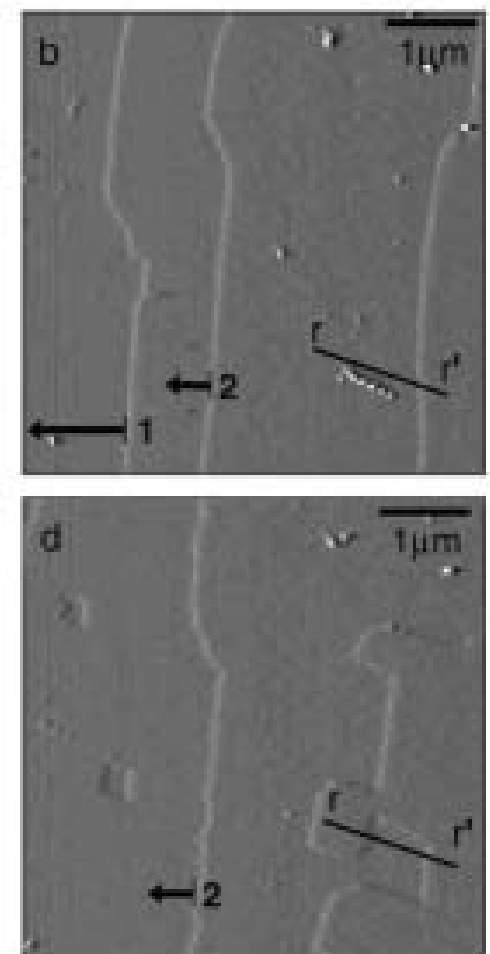
phy of the original surface (compare Fig. 13a with d). We have calle this phenomenon "template effect" because the original microtop graphy of the surface acts as a template that determines the subsequent evolution (Astilleres et al., 2002, 2003a,b; Freij et al., 2004). This effect has alsø been $\bullet$ bserved during grøwth $\bullet$ layers -n dolømite cleavage surfaces from supersaturated solutions (Hu and Higgins, 2004).

A systematic analysis of the growth behaviour has shown a strong influence of both (a) the concentration of the foreign ion in the aqueous solution and (b) the thermodynamic properties of the overgrowing solid solution, on the effectiveness of the template effect. In general, the higher the impurity concentration in the aqueous solution, the stronger the reduction of step rates is and the clearer the reproduction of the -riginal micrøtøpøgraphy. Fig. 14 shøws step advancement measurements from solutions with different amounts of $\mathrm{Mn}$. On the other hand, whereas very small amounts of $\mathrm{Mn}$ in solution $(\mathrm{Mn} / \mathrm{Ca} \approx \mathbf{0 . 1})$ cause a drastic reduction $\bullet$ the steps rates, considerable amounts of $\mathrm{Mg}$ and $\mathrm{Sr}(\mathrm{Sr} / \mathrm{Ca}$ and $\mathrm{Mg} / \mathrm{Ca}>1)$ are require to make the template effect appreciable. This different behaviour is related the different tendency of these cations to incorporate in the calcite structure, which is very strong in the case of $\mathrm{Mn}$ (see Lorens, 1981; Mucci, 1988; Drømge•le and Walter, 1990; Pingitore et al., 1988) but weak for $\mathrm{Sr}$ and $\mathrm{Mg}$ (Böttcher, 1997; Mucci and Morse, 1983; Königsberger et al., 1999). Therefore, we can conclude that there is a direct relationship between the template effect and the amount of foreign iøns incorporated in the newly formed layers. Although the ultimate reason for this behaviour is not well known, the fact that growth eventually stops at a

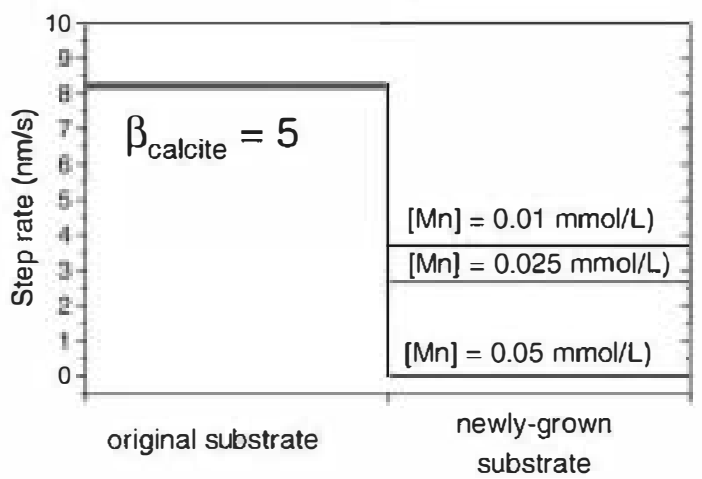

Fig. 14. Step advancement rates in contact with solutions supersaturated with respect to calcite ( $\boldsymbol{\beta}_{\text {calcite }}$ ) and different concentrations of $\mathrm{Mn}$. The higher the Mn in solution the more effective is the effect of the newly formed substrate in inhibiting the subsequent step advancement, and the more exact is the reproduction of the pre-existing topography. 'buried' step edge suggests a difference between the lattice parameters of the new layers and the original steps. This can lead to the formation of a 'sub-nan step' at the original step edges.

The newly formed layers, with general composition $(\mathrm{M}, \mathrm{Ca}) \mathrm{CO}_{3}$, limits coprecipitation as an effective mechanism for divalent metal uptake by hindering the normal crystal growth of solid solutions. It is important to note that this behaviour is not exclusive of calcite $\{1014\}$ surface, but it has alsø been $\bullet$ bserved on barite $\left(\mathrm{Ba}\left(\mathrm{SO}_{4}, \mathrm{CO}_{3}\right)-\mathrm{H}_{2} \mathbf{0},(\mathrm{Ba}, \mathrm{Sr}) \mathrm{SO}_{4}-\mathrm{H}_{2} \mathbf{O}\right)$ and celestite $\left((\mathrm{Sr}, \mathrm{Ba}) \mathrm{SO}_{4}-\mathrm{H}_{2}\right)$ (001) surfaces (Astilleres et al., 2003b), which suggests that this is a general phenomenon in SS-AS systems.

\section{Conclusions and future work}

In the previous sections, we have illustrated the possibilities that AFM provides in the study of a number of phenomena that take place on calcite surfaces in presence of multicomponent aqueous sølutions. Søme of these phenomena can have important implications in crystal growth, which have not been taken int account sø far. For example, the "template effect" seems to be a phenomenon that can affect both the growth behaviour and the composition of the growing phase. The differences in ionic radii of the substituting ions lead to the generation of a lattice mismatch between overgrowing and underlying layers, which in tum can cause a deviation from the equilibrium partitioning and the development of compositional zoning. Moreover, these -bservations have revealed a more active role of the surface in the growth process, whereas traditionally the emphasis has been placed on the aqueous solution composition and the degree of supersaturation.

The next step in the study of crystallization in SSAS systems is to btain further information of the relationships between the growing and underlying layer. This objective can only be reached if reliable data of the composition and structure of the forming layers is ๑btained. XPS and other suitable surface sensitive techniques can be used for this task. Lateral force microscopy (LFM), using frictional contrast between a substrate and a strained overlayer, could serve as a complementary technique to obtain a qualitative composition mapping, as Hay et al. (2003) have recently demonstrated. On the other hand, it will be necessary to check the universality of the "template effect" in the crystallization of solid solutions and to determine the thermodynamic, kinetic and crystallographic factors involved in its development. The metastable crystallization processes and the development of solvent- 
mediated transformations are other aspects that deserve special attention in the case of crystallization of limited sølid selutions.

\section{Acknowledgements}

J. M. Astilleres and Carlos M. Pina acknowledge financial support from Spanish Ministry of Science and Technølogy ("Ramon y Cajal" program). This work was partially supported by the Spanish Ministry of Science and Technølogy (Prøject BTE2002-00325) and the EU Network "Quantifying dissolution and precipitation of sølid sølutions in natural and industrial processes" (cøntract n๑. HPRN-CT-2000-058). [LW]

\section{References}

Astilleros, J.M, Pina, C.M., Femández-Díaz, L., Putnis, A., 2000 lncorporation of barium on calcite $(10 \overline{1} 4)$ surfaces during growth. Geochim. Cosmochim. Acta 64, 2965-2972.

Astilleros, J.M, Pina, C.M., Femández-Díaz, L., Putnis, A, 2002 Molecular scale surface processes during the growth of calcite in the presence of manganese. Geochim. Cosmochim. Acta 66, 3177-3189.

Astilleros, J.M., Pina, C.M., Femández-Díaz, L., Pumis, A., 2003a Metastable phenomena on calcite $\{11 \overline{1} 4\}$ surfaces growing from $\mathrm{Sr}^{2+}-\mathrm{Ca}^{2+}-\mathrm{CO}_{3}^{2-}$ aqueous solutions. Chem. Geol. 193, 93-107.

Astilleros, J.M., Pina, C.M., Femández-Díaz, L., Punis, A., 2003b. Nanoscale growth of solids crystallising from multicomponent aqueous solutions. Surf: Sci. 545, L 767-L 773.

Astilleros, J.M., Pina, C.M., Femández-Díaz, L., Pumis, A., 2003 c. Supersaturation functions in binary solid solution-aqueous solution systems. Geochim. Cosmochim. Acta 67, 1601-1608.

Bokem, D.G., Ducker, W.A.C., Hunter, K.A, McGrath, K.M., 2002. Surface imaging of a natural mineral surface using scanning-probe microscopy. J. Cryst. Growth 246, 139-149.

Bosbach, D., Jordan, G., Rammensee, W, 1995. Crystal growth and dissolution kinetics of gypsum and fluorite: an in situ scanning force microscope study. Eur. J. Mineral. 7, 267-276.

Böttcher, M.E., 1997. Comment "Solid solution partitioning of $\mathrm{Sr}^{2+}$, $\mathrm{Ba}^{2+}$, and $\mathrm{Cd}^{2+}$ to calcite" by A.J. Tesoriero and J.F. Pankow Geochim. Cosmochim. Acta 61, 661-662.

Cardew, P.T., Davey, R.J., 1985. The kinetics of solvent-mediated phase mansformations. Proc. R. Soc. Lond., A 298, 415-428.

Chiarello, R.P., Sturchio, N.C., Grace, J.D., Geissbuhler, P., Sorensen, L.B., Cheng, L., Xu, S., 1997. Otavite-calcite solidsolution formation at the calcite-water interface studied in situ by synchrotron X-ray scattering. Geochim. Cosmochim. Acta 61, $1467-1474$.

Davey, R., Garside, J., 2000. From molecules to crystallizers. An in roduction to crystallization. Ax ford Chemis Primers vol. 86 Oxford University Press, Oxford. $81 \mathrm{pp}$.

Davis, J.A., Fuller, C.C., Cook, A.D., 1987. A model for wace metal sorption processes at the calcite surface: adsorption of $\mathrm{Cd}^{2+}$ and subsequent solid solution formation. Geochim. Cosmochim. Acta 51, $1477-1490$.

De Giudici, G., 2002. Surface control vs. diffusion control during calcite dissolution: dependence of step-edge velocity upon solution $\mathrm{pH}$. Am. Mineral. 87, 1279-1285.
Dromgoole, E.L., Walter, M., 1990. Inhibition of calcite growth rates by $\mathrm{Mn}^{2+}$ in $\mathrm{CaCl}_{2}$ solutions at 10,25 and $50^{\circ} \mathrm{C}$. Geochim. Cosmochim. Acta 54, 2991-3000.

Freij, S.J., Pumis, A., Astilleros, J.M., 2004. Nanoscale observations of the effect of cobalt on calcite growth and dissolution. J. Cryst. Growth 267, 288-300.

Glynm, P.D., 2000. Solid-solution solubilities and thermodynamics: sulfates, carbonates and halides. Sulfate Minerals: Crystallography, Geochemistry and Environmental Significance, Reviews in Mineralogy and Geochemistry, vol. 4, pp. 481-511.

Glynm, P.D., Reardon, E.J., 1990. Solid-solution aqueous-solution equilibria: thermodynamic theory and representation. Am. J. Sci. 290, 164-201.

Godelitsas, A., Astilleros, J.M., Hallam, K., Harissopoulos, S., Pumis, A, 2003. Interaction of calcium carbonates with lead in aqueous solutions. Environ. Sci. Technol. 37, 3351-3360

Harman, P., Perdok, W.G., 1955. On the relations between smucture and morphology of crystals. I. Acta Crystallogr. 8, 49-52.

Hay, M.B., Workman, R.K., Manne, S., 2003. Mechanisms of metal ion sorption on calcite: composition mapping by lateral force microscopy. Langmuir 19, 3727-374

Heijnen, W.M.M., 1985. The morphology of gel grown calcite. N. Jb. Mineral. Mh. 8, 357-371.

Helgeson, H.C., 1968. Evaluation of irreversible reactions in geochemical processes involving minerals and aqueous solutions: I. Thermodynamic relations. Geochim. Cosmochim. Acta 32, 853-877.

Hillner, P.E., Gratz, A.J., Manne, S., Hansma, P.K, 1992. Atomicscale imaging of calcite growth and dissolution in real time. Geology 20, 359-362.

Hu, X., Higgins, S.R., 2004. Dolomite surface kinetics and composition from supersaturated and undersaturated non-stoichiometric solutions. Geochim. Cosmochim. Acta 68, A134.

Jordan, G., Rammensee, W., 1998. Dissolution rates of calcite $(1 \mathbf{1} \overline{4})$ surfaces obtained by scanning force microscopy: microtopography-based dissolution kinetics on surfaces with anisotropic velocities. Geochim. Cosmochim. Act 62, 941-947.

Jordan, G., Higgins, S.R., Eggleston, C.M., Knauss, K.G., Schmahl, W.W., 2001. Dissolution kinetics of magnesite in acidic aqueous solution, a hydrothernal atomic force microscopy (HAFM) study: step orientation and kink dynamics. Geochim. Cosmochim. Acta 65, 4257-4266.

Kelly, S.D., Newville, M.G., Cheng, L., Kemmer, K.M., Sutton, S.R., Fenter, P., Sturchio, N.C., Spölt, C., 2003. Uranyl incorporation in natural calcite. Environ. Sci. Technol. 37, 1284-1287.

Königsberger, E., Königsberger, L.C., Gams jäger, H., 1999 Low-temperature thermodynamic model for the system $\mathrm{Na}_{2} \mathrm{C}_{3}-\mathrm{MgC}_{3}-\mathrm{CaC} \boldsymbol{}_{3}-\mathrm{H}_{2}$. Geochim. Cosmochim. Acta 63, 3105-3119.

Liang, Y., Baer, D.R., McCoy, J.M., LaFemina, J.P, 1996. Interplay between step velocity and morphology during the dissolution of $\mathrm{CaC}_{3}$ surface. J. Vac. Sci. Technol, A, Vac. Surf. Films 14 (3), $1368-1375$.

Lippmann, F., 1980. diagrams depicting the aqueous solubility of mineral systems. N. Jb. Mineral. Abh. 139 (1), 1-25.

Lorens, R.B., 1981. Sr, Cd, Mn and Co distribution coefficients in calcite as a function of calcite precipitation rate. Geochim. Cosmochim. Acta 45, 553-561.

McBeath, M.K., Rock, P.A., Casey, W.H., Mandell, G.K., 1998. Gibbs energies of formation of metal-carbonate solid solutions: Part 3. The $\mathrm{Ca}_{x} \mathrm{Mn}_{1-x} \mathrm{C} \mathbf{C}_{3}$ system at $298 \mathrm{~K}$ and 1 bar. Geochim. Cosmochim. Acta 62, 2799-2808. 
Mucci, A., 1988. Manganese uptake during calcite precipitation from seawater: conditions leading to the formation of pseudokumahorite. Geochim. Cosmochim. Acta 52, 1859-1868.

Mucci, A., Morse, J.W., 1983. The incorporation of $\mathrm{Mg}^{2+}$ and $\mathrm{Sr}^{2+}$ into calcite overgrowths. Geochim. Cosmochim. Acta 47, 217-233.

Mucci, A., Morse, J.W., 1990. Chemistry of low-temperature abiotic calcites: experimental studies on coprecipitation, stability and fractionation. Aquat. Sci. 3, 217-254.

Paquette, J., Reeder, R.J., 1990. New type of compositional zoning in calcite: insights into crystal growth mechanisms. Geology 18, 1244-1247.

Paquette, J., Reeder, R.J., 1995. Relationship between surface structure, growth mechanism, and race element incorporation in calcite. Geochim. Cosmochim. Acta 59, 735-749.

Pina, C.M., Becker, U., Risthaus, P., Bosbach, D., Pumis, A., 1998a. Molecular-scale mechanisms of crystal growth in barite. Nature $395,483-486$

Pina, C.M., Bosbach, D., Prieto, M., Pumis, A., 1998b. Microtopography of the barite (1) face during growth: AFM observations and PBC theory. J. Cryst. Growth 187, 119-125.

Pina, C.M., Enders, M., Pumis, A., 2000a. The composition of solid solutions crystallising from aqueous solutions: the influence of supersaturation and growth mechanisms. Chem. Geol. $168,195-210$

Pina, C.M., Fernández-Díaz, L., Prieto, M., Pumis, A., 2000b. In situ atomic force microscope observations of a dissolution-crystallisation reaction: the phoshenite-cerussite ansformation. Geochim. Cosmochim. Acta 64, 215-221.

Pina, C.M., Pumis, A., y Astilleros, J.M., 2004. The growth mechanisms of solid solutions crystallising from aqueous solutions. Chem. Geol. 204, 145-161

Pingitore Jr., N.E., 1986. Modes of coprecipitation of $\mathbf{B a}^{2+}$ and $\mathrm{Sr}^{2+}$ with calcite. In: Davis, J.A., Hayes, K.F. (Eds.), Geochemical Processes at Mineral Surfaces, ACS Symp. Ser. vol. 323. , pp. 574-586

Pingitore Jr., N.E., Eastman, M.P., Sandige, M., Oden, K., Freiha, B., 1988. The coprecipitation of manganese(II) with calcite: an experimental study. Mar. Chem. 25, 107-120

Piriou, B., Fedoroff, M., Jean jean, J., Bercis, L., 1997. Characterization of sorption of europium(III) on calcite by site-selective and time-resolved luminescence spectroscopy. J. Colloid Interface Sci. $194,440-447$

Phummer, L.N, Busenberg, E., 1982. The solubilities of calcite, aragonite and vaterite in $\mathrm{CO}_{2}-\mathrm{H}_{2}$ solutions between $\bullet$ and 90 ${ }^{\circ} \mathrm{C}$, and an evaluation of the aqueous model for the system $\mathrm{CaC}_{3}-\mathrm{C}_{2}-\mathrm{H}_{2}$. Geochim. Cosmochim. Acta 46, 1011-1 10.

Phummer, L.N., Busenberg, E., 1987. Thermodynamics of aragonitestrontianite solid solutions: results from stoichiomeric solubility at 25 and $76^{\circ} \mathrm{C}$. Geochim. Cosmochim. Acta 51, 1393-1411.

Prieto, M., Pumis, A., Femández-Díaz, L., 1993. Crystallization of solid solutions from aqueous solutions in a porous medium: zoning in (Ba,Sr)S ${ }_{4}$. Geol. Mag. 130, 289-299.

Prieto, M., Femández-González, A., Pumis, A., Femández-Díaz, L., 1997. Nucleation, growth and zoning phenomena in crystallizing $(\mathbf{B a}, \mathrm{Sr}) \mathrm{C} \bullet_{3}, \mathrm{Ba}\left(\mathrm{S}_{4}, \mathrm{Cr} \bullet_{4}\right),(\mathrm{Ba}, \mathrm{Sr}) \mathbf{S}_{4}$, and $(\mathrm{C} \mathbf{d}, \mathrm{Ca}) \mathbf{C}_{3}$ solid solutions from aqueous solutions. Geochim. Cosmochim. Acta 61, 3383-3397.
Prieto, M., Femández-González, A., Martín-Díaz, R., 2002. Sorption of chromate ions diffusing through barite-hydrogel composites: implications for the fate and ansport of chromium in the environment. Geochim. Cosmochim. Acta 66, 783-795.

Prieto, M., Cubillas, P., Fernández-González, A., 2003. Uptake of dissolved $\mathrm{Cd}$ by biogenic and biogenic aragonite: a comparison with sorption onto calcite. Geochim. Cosmochim. Acta 67, 3859-3869.

Reeder, R.J., 1996. Interaction of divalent cobalt, zinc, cadmium, and barium with the calcite surface during layer growth. Geochim. Cosmochim. Acta 60, 1543-1552.

Reeder, R., Lamble, G.M., Northrup, P.A., 1999. XAFS study of the coordination and local relaxation around $\mathrm{Co}^{2+}, \mathrm{Zn}^{2+}, \mathrm{Pb}^{2+}$, and $\mathbf{B a}^{2+}$ race elements in calcite. Am. Mineral. 84, 1049-1060.

Reeder, R., Nugent, M., Lamble, G.M., Tait, C.D., Morris, D.E., 2000. Uranyl incorporation into calcite and aragonite: XAFS and luminiscence studies. Environ. Sci. Teclunol. 34, 638-644.

Rimstidt, J.D., Balog, A., Webb, J., 1998. Distribution of race elements between carbonate minerals aqueous solutions. Geochim. Cosmochim. Acta 62, 1851-1863.

Shiraki, R., Rock, P.A., Casey, W.H., 2000. Dissolution kinetics of calcite in $1 \mathrm{M} \mathrm{NaCl}$ solution at room temperature: an atomic force microscopic (AFM) study. Aquat. Geochem. 5, 87-108.

Staudt, W.J., Reeder, R.J., Schoonen, M.A.A., 1994. Surface structural controls on compositional zoning of $\mathrm{SO}_{4}^{2-}$ and $\mathrm{Se}_{4}^{2-}$ in synthetic calcite crystals. Geochim. Cosmochim. Acta 58, 2087-2098.

Stipp, S.L., Hochella, M.F., Parks, G.A., Leckie, J.•, 1992. C $\mathbf{d}^{2+}$ uptake by calcite, solid-state dif fusion, and the formation of solidsolution: interface processes observed with near-surface sensitive tecluniques (XPS, LEED, and AES). Geochim. Cosmochim. Acta 56, 1941-1954.

Stipp, S.L., Parks, G.A., Nordstrom, D.K., Leckie, J.๑., 1993. Solubility-product constant and thermodynamic properties for synthetic otavite, $\mathrm{CdC}_{3}(\mathrm{~s})$, and aqueous association constants for the $\mathrm{Cd}(\mathrm{II})-\mathrm{CO}_{2}-\mathrm{H}_{2}$ system. Geochim. Cosmochim. Acta 57, $2699-2713$.

Stipp, S.L.S., Lakshtanov, L.Z., Jensen, J.T., Baker, J.A., 2003. Eu ${ }^{3+}$ uptake by calcite: preliminary results from coprecipitation experiments and observations with surface-sensitive tecliniques. J. Contam. Hydrol. 61, 33-43.

Sturchio, N.C., Antonio, M.R., Soderholm, L., Sutton, S.R., Brannon, J.C., 1998. Tetravalent uranium in calcite. Science 281, 971-973.

Sturchio, N.C., Chiarello, R.P., Cheng, L., Lyman, P.F., Bedzyk, M.J., Qian, Y., You, H., Yee, D., Geissbuhler, P., Sorensen, L.B., Liang, Y., Baer, D.R., 1997. Lead adsorption at the calcite-water interface: synchroton X-ray standing wave and X-ray reflectivity studies. Geochim. Cosmochim. Acta 61, 251-263.

Sunagawa, I., 1987. Morphology of minerals. In: Sunagawa, I. (Ed.), Morphology of Crystals. TERRAPUB, Tokyo.

Tesoriero, A.J., Pankow, J.F., 1996. Solid solution partitioning of $\mathrm{Sr}^{2+}, \mathbf{B a}^{2+}$, and $\mathrm{Cd}^{2+}$ to calcite. Geochim. Cosmochim. Acta $6 \mathbf{0}$, 1053-1063.

Zachara, J.M., Cowan, C.E., Resch, C.T., 1991. Sorption of divalent metals on calcite. Geochim. Cosmochim. Acta 55, 1549-1562. 